\title{
Respiratory Mechanics and Dust Exposure in Byssinosis
}

\author{
A. BoumuYs and K. P. van DE Woestijne with the technical assistance of \\ G. KANE and J. vaN WAYENBURG \\ From the John B. Pierce Foundation Laboratory and the Departments of \\ Medicine and of Epidemiology and Public Health, Yale University School of \\ Medicine, New Haven, Connecticut 06510
}

A B S T R A C T Acute exposures to hemp dust, in healthy subjects as well as hemp workers with byssinosis, resulted in two different responses. Men with symptoms (chest tightness, coughing, and wheezing) after exposure showed decreases of forced expiratory volumes $\left(F V_{1.0}\right)$, flow rates on maximum expiratory flow-volume (MEFV) curves, and of vital capacity (VC), while airway conductance (Gaw: TGV ratio) did not decrease significantly ("flow rate response"). Men without symptoms after exposure showed no changes of VC, FEV 1.o, and MEFV curves, but had a significantly decreased airway conductance ("conductance response"). The flow rate response is attributed to a pharmacological bronchoconstrictor effect of hemp dust on small airways, the conductance response to a mechanical or reflex effect of hemp dust on large airways. Both responses were abolished by a bronchodilator drug. The type of response reflects a difference between individuals and is not related to age, smoking habits, or prior exposure history. Men with normal control function data had either a flow rate or a conductance response. All men with abnormal control data had a flow rate response.

Long-term hemp dust exposure causes irreversible obstructive lung disease, in particular among men who respond to acute dust exposure with symptoms and flow rate decreases. The detection of this response, with $\mathrm{FEV}_{1.0}$ measurements and MEFV curves, is essential in the study of byssinosis. Decreases of airway conductance after dust exposure have no consistent relation to the development of clinical symptoms. The relative value of measurements of maximum expiratory flow rates and of airway conductance in other lung diseases needs to be reassessed.

Presented in part at the meeting of the American Federation for Clinical Research, Atlantic City, N. J., 5 May 1968 (Clin. Res. 16: 376).

Dr. van de Woestijne's present address is Laboratorium voor Longfunctieonderzoek, Academisch Ziekenhuis "St. Rafael," Capucijnenvoer, Leuven, Belgium.

Received for publication 1 April 1969 and in revised form 16 July 1969.

\section{INTRODUCTION}

Many workers exposed to dust of soft hemp (Cannabis sativa) in industry develop byssinosis $(1,2)$. The symptoms of this occupational lung disease resemble those of bronchial asthma but occur under predictable conditions, i.e. chiefly during a first exposure to dust after absence from the dusty environment for more than a day, i.e., usually on Monday. They are accompanied by lung function changes which suggest obstructive ventilatory impairment $(3,4)$. These changes can be reversed within $1 / 2 \mathrm{hr}$, at least in part, by inhalation of isoproterenol $(5,6)$. Since production of sputum is absent or minimal, contraction of bronchial smooth muscle is probably the main cause of the acute effects of the dust.

These effects of dust exposure in man afford an opportunity to study the acute development of changes in lung mechanics caused by an environmental agent which is known to cause chronic lung disease after many years of exposure (2). However, most previous studies in the industry have been limited to relatively simple tests $(1,3$, $6)$. We used a body plethysmograph to obtain additional information and were thus able to correlate the results of several different tests which reflect the mechanical properties of the lungs. The results suggest that two different acute responses to hemp dust exposure can be distinguished; only one of these appears to be associated with the development of chronic obstructive lung disease, a common sequel to the acute stages of byssinosis.

\section{METHODS}

Working conditions. The study was performed in Callosa de Segura, Spain. Conditions in the hemp industry in that town and the high prevalence of byssinosis and chronic obstructive lung disease among certain categories of hemp workers have been described in previous papers $(1,2)$. The subjects for the present study were chiefly recruited among those who participated in the previous studies. The pulmonary function studies were performed in a field laboratory with facilities for physical examinations, spirometry, and body plethysmography. 
Subjects. 33 hemp workers and 6 healthy subjects (staff members) participated in the experiments. All were studied after at least 2 days absence from the dusty work rooms, to avoid the tachyphylaxis induced by recent dust exposure. Since we anticipated sizable reductions of ventilatory capacity during dust exposure in at least some subjects, we did not include anyone with a control forced expiratory volume $\left(\mathrm{FEV}_{1.0}\right)$ of less than 1.50 liters in the present study. Also, only men whose forced expiratory maneuvers were sufficiently reproducible were included.

Methods. FEV $\mathrm{FE}_{1.0}$ and forced expiratory vital capacity (FVC) were measured with portable spirometers with transistorized timers. ${ }^{1}$ The average of the two highest values among five blows was taken as the result for both $F E V_{1.0}$ and FVC. All vital capacities (VC) in this paper are FVC's.

Thoracic gas volume (TGV) and airway resistance (Raw) were measured with DuBois' techniques, using a volume displacement body plethysmograph, as described in previous papers from this laboratory $(7,8)$. Total lung capacity (TLC) was calculated (average of 3-6 measurements) from the measurements of $\mathrm{TGV}$ and the simultaneous recording of lung volume events. This value of TLC was also used to determine the lung volume level at which Raw determinations were performed. All measurements of Raw were done after the subject had first inspired to TLC and then expired to the desired lung volume level. Determinations of Raw were done at different lung volume levels in each subject and under each condition. At the end of each Raw measurement, the subject inspired to TLC to check for changes in lung volume during panting. Technically inadequate measurements were rejected at the time of the experiments; all other data are included in the analysis. All TGV and Raw readings were made by the same observer. The calibrations of volume, flow, and pressure signals were checked daily before and after each series of experiments. In healthy subjects, serial determinations of TLC yielded values which varied 0.2 liter or less; the same was true in most hemp workers. This provided a further check on the accuracy of the TGV measurements. For statistical purposes, the airway resistance values were expressed as the ratio of condustance over thoracic gas volume (Gaw: TGV ratio). All airway conductance values were corrected for the resistance of the breathing circuit.

Maximum expiratory flow-volume (MEFV) curves were recorded with two methods. The first uses the body plethysmograph; lung volume changes, from the plethysmograph, were plotted vs. maximum expiratory flow rates (from a flowmeter at the mouth) during maximally rapid expirations starting at TLC. Volume and flow signals were displayed on a storage oscilloscope, ${ }^{2}$ and the resulting curve was photographed. The second method uses a new flow-volume spirometer (9), designed for field studies. It writes an XY recording of the MEFV curve on a $3 \times 5$ inch index card. Its pen excursions along the flow axis are linear with flow rate up to about 8 liters/sec. Calibrations (with a calibrated orifice and pump) were stable on any given day but varied about $10 \%$ from day-to-day. These variations were taken into account in the calculations. To compare the two methods, we connected the flow-volume spirometer to the flow meter on the body plethysmograph. With a subject in the plethysmograph, we could thus record MEFV curves with both methods during the same expiration. After correction for the curvilinear recording of the spirometer (Fig. $1 \mathrm{~B}$ and C), the curves in a healthy subject were nearly superim-

\footnotetext{
1 Poulton \& Son, Barry, Glamorgan, U. K.

${ }^{2}$ Model 564, Tektronix, Inc., Beaverton, Ore.
}

posable with forced as well as submaximal expirations. We used either one or both methods in all experiments. To evaluate effects of dust we only used sets of two or three nearly superimposable curves with the same method in each subject, and from those, we analyzed the curve with the highest flow rates.

Bronchoconstrictor aerosols affect maximum flow rates at defined and constant levels of lung inflation more than other measurements on MEFV curves, such as that of the slope of the effort-independent portion (7). Since we obtained TLC in all subjects, we could compare MEFV curves, e.g. before and after dust, on a thoracic gas volume scale. We could thus read flow rates at equal lung volumes under all conditions; a convenient volume for this purpose is that which equals $60 \%$ of the control TLC. We have called this flow rate $\mathrm{V}_{\max }$ at $60 \%$ TLC. In the present study, changes of TLC after dust or bronchodilator were small and, on the average, not significant. Therefore, we also compared the MEFV curves by superimposing them at the TLC point (Fig. 1). Since TLC is constant, readings of maximum flow at TLC minus a constant volume (e.g. $50 \%$ of the control $\mathrm{VC}, \mathrm{V}_{\max }$ at $50 \% \mathrm{VC}$ ) also represent flow rates at constant lung inflation. Both $V_{\max }$ at $60 \%$ TLC and $V_{\max }$ at $50 \% \mathrm{VC}$ have been used in this study. In addition to these two flow rates on the effort-independent portion of the MEFV curve, we measured the peak expiratory flow rate (PEFR), from the same curves.

Static lung recoil curves were obtained before and after dust in two subjects, using a method previously described (10).

Dust exposure. Dust concentrations in hemp factories where men are affected by byssinosis varied from 1.2 to 6.4 $\mathrm{mg} / \mathrm{m}^{3}$ in a previous study (1); there was no clear relation between dust levels and prevalence of symptoms or changes of $\mathrm{FEV}_{1.0}$. The factory rooms used for the present exposures were visually very dusty, and since we were only interested in studying man's response, we did not repeat the dust measurements. On each day, we studied several men exposed at the same time and in the same room. On all days one or more men reacted to dust exposure with symptoms and lung function changes; this was taken as evidence that the exposures were effective.

Procedures. The subjects came to the laboratory early in the morning. After appropriate instructions, we first measured TLC and Gaw in the body plethysmograph; next we recorded MEFV curves, and finally $\mathrm{FEV}_{1.0}$ and $\mathrm{VC}$ with the portable spirometer. This sequence was used for measurements after dust and bronchodilator as well. Thus, each subject had made several maximum inspirations before his MEFV curves were recorded, but only a few at the time that conductance was measured. After the control measurements, the subjects were taken to a hemp factory and were requested to spend, if possible, 2 or more hr in a dusty room. They were told to leave the area at any time if they experienced severe symptoms. All hemp workers who reacted to dust were familiar with these symptoms from previous experience. Postexposure measurements were performed within $30 \mathrm{~min}$ after the termination of exposure. In most subjects, further measurements were made at least 20 min after administration of an isoproterenol-phenylephrine mixture by hand nebulizer (two doses, Medihaler-Duo), which was given when the post-dust data were completed. Three men who did not react subjectively to dust while at rest were exposed again on another day, while they exercised on a bicycle ergometer during periods of $15 \mathrm{~min}$ (300$450 \mathrm{kpm} / \mathrm{min}$ ) alternating with $15 \mathrm{~min}$ rest. All dust ex- 
TABLE I

Average Control Lung Function Data in Hemp Workers

\begin{tabular}{|c|c|c|c|}
\hline & Men $<45 \mathrm{yr}$ & Men $>45 \mathrm{yr}$ & $P$ \\
\hline n & 14 & 14 & . \\
\hline Age, $y r$ & 34.6 & 55.1 & \\
\hline Height, $\mathrm{cm}$ & 167.9 & 167.3 & NS \\
\hline Time in industry, yr & 18.1 & 35.0 & $<0.01$ \\
\hline FEV 1.0 , liters & 3.30 & $2.32^{+}$ & \\
\hline FEV $1,0, \%$ of predicted & 90.4 & 78.5 & $<0.05$ \\
\hline VC, liters & 4.49 & $3.55^{*}$ & \\
\hline VC, $\%$ of predicted & 100.9 & 90.8 & NS \\
\hline TLC, liters & 6.21 & $6.69^{+}$ & \\
\hline TLC, $\%$ of predicted & 107.5 & 116.4 & NS \\
\hline RV, liters & 1.72 & $3.15^{+}$ & \\
\hline RV, \% of predicted & 120.3 & 185.2 & $<0.01$ \\
\hline RV:TLC, \%, actual & 27.7 & $45.4^{+}$ & $<0.01$ \\
\hline PFFR, liters $/ \mathrm{sec}$ & $6.81(13)$ & 5.29 & $<0.05$ \\
\hline$\dot{\mathrm{V}}_{\max }$ at $50 \%$ VC, liters $/ \mathrm{sec}$ & $3.78(13)$ & 2.08 & $<0.01$ \\
\hline$\dot{\mathrm{V}}_{\max }$ at $60 \%$ TLC, liters $/ \mathrm{sec}$ & $3.00(13)$ & 0.94 & $<0.01$ \\
\hline Gaw:TGV, $1 / \mathrm{cm} \times \mathrm{sec}$ & $0.136(12)$ & 0.117 (13) & NS \\
\hline FEV $1.0 / V C, \%$ & 73.1 & 65.4 & NS \\
\hline
\end{tabular}

Abbreviations used: FEV1.0, forced expiratory volume; MEFV, maximum expiratory flow-volume; VC, vital capacity; TLC, total lung capacity; RV, residual volume; PEFR, peak expiratory flow rate; Gaw, airway conductance; TGV, thoracic gas volume; Raw, airway resistance. $n=$ number of men (exceptions in parentheses). \% of predicted $=$ in $\%$ of values expected for age and height (11). Significance of difference between average values in younger and older men is shown in column four, using percentages of predicted values where available (NS = not significant)

* Values for FEV 1,0, VC, TLC, RV, and RV:TLC that differ significantly from predicted values, $P<0.05$; plus sign $\left(^{+}\right)$denotes $P<0.01$.

posures were supervised by team members and by supervisors in the factories. Incomplete data were obtained in some subjects; this is reflected in the numbers of subjects shown in each Table.

\section{RESULTS}

Control lung function data (Table I). Among the younger hemp workers $(<45 \mathrm{yr}), \mathrm{FEV}_{1.0}$ and lung volumes did not differ significantly from the values expected for their age and body height from the data of the Veterans Administration cooperative study (11). The older men, however, had a significantly smaller than predicted $\mathrm{FEV}_{1.0}$ and $\mathrm{VC}$ and a larger than predicted TLC, residual volume (RV), and RV:TLC ratio. As a percentage of the predicted values, FEV $\mathrm{F}_{1.0}$ was significantly lower and $\mathrm{RV}$ higher among the older men than among the younger group. PEFR, $\nabla_{\max }$ at $50 \%$, and $\mathrm{V}_{\max }$ at $60 \%$ TLC were all significantly lower among the older men; these differences reflect, at least partially, the physiological decrease of maximum flow rates with age. No suitable prediction data are available to take the effect of age into account. The Gaw: TGV and $\mathrm{FEV}_{1.0}$ : VC ratios were slightly, but not significantly, lower among the older men. Only four of the older and none of the younger men could be classified as having at least moderately severe chronic obstructive lung disease, with a $\mathrm{FEV}_{1.0}$ less than $70 \%$ of predicted and an RV: TLC ratio of more than $50 \%$. Randomly selected groups of hemp workers include more severely disabled men than the present group (2).

Effects of dust exposure. Complete data before and after dust exposure were obtained in 30 experiments with 25 subjects. Three representative examples of responses to dust are shown in Fig. 1. The average data from all experiments are summarized in Table II.

TABLE II

Lung Function Changes

\begin{tabular}{cccccc}
\hline & & & & & \\
Group & $\mathrm{n}$ & $\Delta \mathrm{FEV}_{1.0}$ & $\Delta \mathrm{VC}$ & $\Delta \mathrm{TLC}$ & $\Delta \mathrm{RV}$ \\
\hline & & liters & liters & liters & liters \\
(A) All experiments & 30 & -0.21 & $-0.20(29)$ & +0.04 & $+0.24(29)$ \\
$P$ & & $(-7.2 \%)$ & $(-4.8 \%)$ & $(+0.5 \%)$ & $(+11.3 \%)$ \\
& & $<0.01$ & $<0.01$ & $\mathrm{NS}$ & $<0.01$ \\
(B) Men with & 24 & -0.26 & -0.26 & 0 & +0.26 \\
chest tightness & & $(-9.1 \%)$ & $(-6.0 \%)$ & $(0 \%)$ & $(+11.8 \%)$ \\
$P$ & & $<0.01$ & $<0.01$ & $\mathrm{NS}$ & $<0.01$ \\
(C) Men without & 6 & +0.01 & $+0.06(5)$ & +0.18 & $+0.17(5)$ \\
chest tightness & & $(+0.3 \%)$ & $(+1.1 \%)$ & $(+2.5 \%)$ & $(+8.9 \%)$ \\
$P$ & & $\mathrm{NS}$ & $\mathrm{NS}$ & $\mathrm{NS}$ & $\mathrm{NS}$ \\
\hline
\end{tabular}

$\mathbf{n}=$ No. of experiments (exceptions in parentheses). Values shown are average differences between measurements before and after dust exposures; negative sign denotes decrease after dust exposure, in absolute values and as a percentage of value before dust (in parentheses). $P=$ probability that changes are due to chance ( $t$ test for paired variates); NS $=$ not significant $(P>0.05)$. 
Two different responses to dust could be distinguished. In several subjects, flow rates throughout a forced expiration (i.e. peak flow rate as well as flows at smaller lung volumes) decreased markedly after dust, while airway conductance decreased relatively little or not at all. For instance in subject $\mathrm{A}$ (Fig. $1 \mathrm{~A}$ ), PEFR and $\nabla_{\max }$ at $50 \% \mathrm{VC}$ decreased $37 \%$ while in dust. At the same time, airway conductance at $\mathrm{TGV}=5.2$ liters decreased $16 \%$, as did the Gaw: TGV ratio. In subject $B$, peak flow did not decrease after dust, but expiratory flow rates at lower lung volumes did. Airway conductance did not decrease. Both subjects complained of chest tightness at the end of dust exposure, and both showed a decrease of flow rates on MEFV curves and of $F_{E V}$ 1.o. Subject $A$ was more severely affected than subject $B$, and this was also reflected in a larger decrease of $\mathrm{FEV}_{\mathbf{1 . 0}}$ in subject A. A qualitatively different response occurred in subject $C$. Here, maximum flow rates as well as $F V_{1.0}$ increased after dust, while airway conductance decreased (Gaw at $\mathrm{TGV}=5.5$ liters: $-24 \%$; Gaw: TGV, $20 \%$ ). This subject had no subjective symptoms at any time during or after exposure. A similar response, i.e. no decrease or increase of flow rates and $F E V_{1.0}$ and a decrease of conductance, was found in all six subjects who had no symptoms during or after exposure. Four subjects complained of chest tightness at the end of exposure but showed little or no change in any one measurement. The remaining 15 subjects complained of chest tightness and showed decreases of flow rates and FEV 1.0, with relatively less or no decrease of conduc- tance. In all subjects, the changes of $F E V_{1.0}$, which were assessed independently, corresponded to those of $\nabla_{\max }$ at $50 \% \mathrm{VC}$ (from the MEFV curve), i.e., large decreases of this flow rate were accompanied by relatively large decreases of $\mathrm{FEV}_{1.0}$ and vice versa. Two different techniques of obtaining MEFV curves (see Methods) showed similar flow rate changes in subjects where both were used.

We will refer to the two types of response as the "flow rate response" (Fig. $1 \mathrm{~A}$ and $\mathrm{B}$ ) and the "conductance response" (Fig. 1 C). The qualitative difference between the two responses in the total material is evident when all experiments (Table II A) are subdivided according to a criterium which is independent of any test result, i.e., the presence (Table II B) or absence (Table II C) of chest tightness at the end of dust exposure. In the total material, all changes of lung volumes (except TLC), FEV 1.0, flow rates, and airway conductance were significant at probability levels varying from 1 to $5 \%$. The same was true for the men with chest tightness (Table II B) except for the airway conductance decrease, which did not reach significant levels. On the other hand, the men without chest tightness ( Table II C) had no significant changes of any one of the measurements, except for a decrease of the Gaw : TGV ratio which was significant at the $1 \%$ level.

Both responses occurred in hemp workers as well as in healthy subjects exposed to dust for the first time in their lives. The type of response was not related to particular conditions which might have existed on certain

After Hemp Dust Exposure

\begin{tabular}{|c|c|c|c|c|c|}
\hline$\triangle \mathrm{PEFR}$ & $\begin{array}{l}\Delta \dot{\mathrm{V}}_{\max } \text { at } \\
50 \% \mathrm{VC}\end{array}$ & $\begin{array}{l}\Delta \dot{\mathrm{V}}_{\max } \text { at } \\
60 \% \text { TLC }\end{array}$ & $\Delta$ Gaw:TGV & $\Delta \frac{\mathrm{FEV}_{1.0}}{\mathrm{VC}}$ & $\begin{array}{c}\text { Time } \\
\text { in } \\
\text { dust }\end{array}$ \\
\hline liters/sec & liters $/ \mathrm{sec}$ & liters/sec & $1 / \mathrm{cm} \times \mathrm{sec}$ & $\%$ & hr:min \\
\hline $\begin{array}{c}-0.41 \\
(-7.0 \%) \\
<0.02\end{array}$ & $\begin{array}{c}-0.47 \\
(-16.4 \%) \\
<0.01\end{array}$ & $\begin{array}{c}-0.36 \\
(-22.5 \%) \\
<0.01\end{array}$ & $\begin{array}{l}-0.014 \\
(-7.6 \%) \\
<0.02\end{array}$ & $\begin{array}{l}-2.1(29) \\
<0.05\end{array}$ & $2: 21$ \\
\hline $\begin{array}{c}-0.53 \\
(-9.2 \%) \\
<0.01\end{array}$ & $\begin{array}{c}-0.61 \\
(-21.5 \%) \\
<0.01\end{array}$ & $\begin{array}{c}-0.38 \\
(-26.8 \%) \\
<0.01\end{array}$ & $\begin{array}{c}-0.010 \\
(-4.7 \%) \\
\text { NS }\end{array}$ & $\begin{array}{l}-2.4 \\
<0.05\end{array}$ & $2: 16$ \\
\hline $\begin{array}{c}+0.10 \\
(+2.0 \%) \\
\text { NS }\end{array}$ & $\begin{array}{c}+0.10 \\
(+3.9 \%) \\
\mathrm{NS}\end{array}$ & $\begin{array}{c}-0.25 \\
(-6.0 \%) \\
\mathrm{NS}\end{array}$ & $\begin{array}{c}-0.031 \\
(-20.1 \%) \\
<0.01\end{array}$ & $\begin{array}{c}-0.8(5) \\
\mathrm{NS}\end{array}$ & $2: 40$ \\
\hline
\end{tabular}



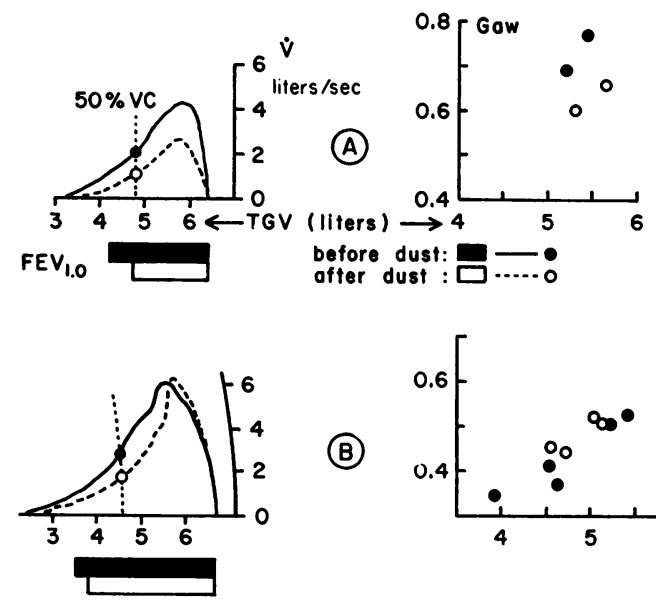

(B)
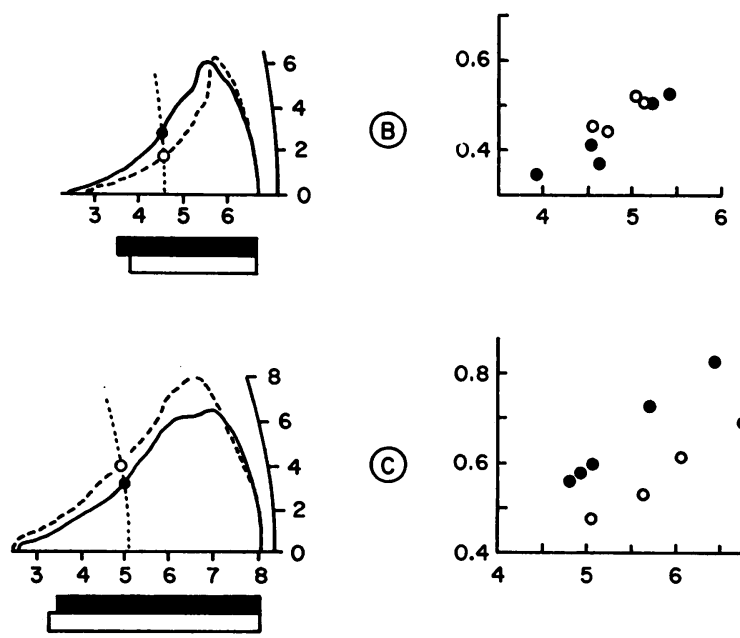

(C)

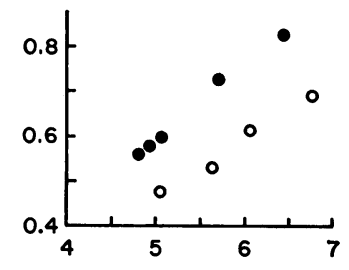

Figure 1 MEFV curves and Gaw-TGV graphs before and after dust in three subjects, A, B, and C. Left-hand graphs, MEFV curves superimposed at TLC. Right hand graphs, airway conductance (Gaw) (liters/sec per $\mathrm{cm} \mathrm{H}_{2} \mathrm{O}$ ) vs. thoracic gas volume (TGV). The curved flow ordinates in the MEFV curves of $\mathrm{B}$ and $\mathrm{C}$ reflect the curvilinear pen excursions of the flow-volume spirometer (9). MEFV curves in A were made with the body plethysmograph. Bars under MEFV curves indicate $\mathrm{FEV}_{1.0}$ before and after dust; refer to TGV scale for volume calibration. Dashed vertical lines indicate volume level for measurements of $\mathrm{V}_{\max }$ at $50 \% \mathrm{VC}$. These flow values are indicated by a dot and a circle on the MEFV curves. The $\mathrm{FEV}_{1.0}$ values from the individual expirations illustrate the consistency of the responses (in liters):
A, before dust : $2.00-2.06-2.11-2.22-2.17$;
$\mathrm{A}$, after dust: $1.66-1.47-1.59-1.56-1.58$
$\mathrm{B}$, before dust : $2.97-3.13-3.06-3.00-2.98$;
$\mathrm{B}$, after dust: $2.76-2.74-2.71-2.85-2.75$.
C, before dust : 4.51-4.53-4.60-4.42-4.44 ;
C, after dust :4.81-4.76-4.70-4.66-4.72.
In $A$ and $B, F E V_{1.0}$ decreased, in $C, F E V_{1.0}$ in- creased, and the changes are highly significant in all three subjects $(P<0.001)$.

days. On each of 4 days, we observed a conductance response in one man and a flow rate response in one or two others exposed in the same room and at the same time. Duration of employment in the hemp industry was not a major factor either. Three men with a conductance response had worked 14-35 $\mathrm{yr}$ in hemp; none of the function changes in dust listed in Table II differed significantly when 13 men with less than $20 \mathrm{yr}$ exposure were compared with 13 others who had worked more than $20 \mathrm{yr}$ in the industry. Other factors which may relate to the type and degree of response to hemp dust are considered in the following paragraphs.

Control lung function data and response to dust (Table III). The 19 men with chest tightness while in dust (Table II B) were subdivided into a group whose control $\mathrm{FEV}_{1.0}$ was $>80 \%$ of the predicted value for height, age, and sex (Table III A) and a group whose control $\mathrm{FEV}_{1.0}$ was considered abnormally low, i.e., $<80 \%$ of predicted (Table III B). The men with a low FEV 1.0 spent about $1 \mathrm{hr}$ less in dust, but their flow rate responses were at least as severe as those in the men with a normal control $\mathrm{FEV}_{\text {1.0. }}$. These data suggest that men with abnormal control function data have a more severe flow rate response than those whose initial data are within normal limits.

Groups A and C (Table III) both have control FEV 1.0 values and lung volumes close to the predicted values. Yet, their responses to dust differ markedly: group A has a flow rate response and group $\mathrm{C}$ a conductance response. Thus, both types of response occur in men with normal control function data.

Smoking habits and response to dust (Table IV). Cigarette smokers and nonsmokers, matched for age and duration of employment, had similar $\mathrm{FEV}_{1.0}$ changes in dust, but $\mathrm{V}_{\max }$ at $50 \%$ VC decreased more in the smokers in spite of a shorter exposure to dust.

Effect of exercise on response to dust (Table $V$ ). Three men were exposed first at rest and again at least 1 wk later, while they exercised on a bicycle ergometer (see Methods). The subjective responses to the exposure did not differ; subjects $A$ and $B$ felt slight chest tightness after both exposures; subject $C$ had no symptoms on either occasion. During the exposure at rest, conductance decreased in all three men (with 26,15 , and $9 \%$ of the control value, respectively). In contrast, the exposure with exercise elicited a slight conductance increase. Flow rate and lung volume changes were minimal on both occasions in subjects B and C. In subject A, however, a flow rate response developed during exercise; his $V_{\max }$ at $50 \%$ VC decreased $39 \%$, VC decreased $8 \%$, and RV increased $39 \%$.

Correlation between function test results during dust exposure. The internal consistency of the data was checked by calculating linear correlation coefficients between the dust-induced function changes. Changes in PEFR, $V_{\max }$ at $50 \% \mathrm{VC}$, and $\mathrm{FEV}_{1.0}$ correlated positively and significantly with one another but not with the changes of the Gaw: TGV ratio. Since this lack of correlation with $\Delta \mathrm{Gaw}$ : TGV might be due to the inclusion of six subjects (Table IIC) whose Gaw:TGV decreased without changes in flow rates, we also calculated these correlation coefficients in the group of 24 ex- 
periments which resulted in chest tightness (Table II B). In this group, there was a tendency for $\Delta \mathrm{Gaw}$ : TGV to increase with increasing severity of the flow rate response, but none of the positive correlations between $\Delta \mathrm{Gaw}: \mathrm{TGV}$ and $\Delta \mathrm{FEV}$ 1.0, $\Delta \mathrm{PEFR}$, or $\Delta \mathrm{V}_{\max }$ at $50 \%$ $\mathrm{VC}$ approached the $5 \%$ significance level.

Static recoil pressures before and after dust exposure. These were measured in one healthy investigator and in one $54 \mathrm{yr}$ old retired hemp worker; both had experienced a flow rate response on previous exposures. In the healthy subject, control data were obtained first (day 1) ; data after dust exposure were recorded on days 2 and 5 , after $2 \frac{1}{2}$ and $3 \mathrm{hr}$ exposure, respectively. On each occasion at least two pressure-volume curves were obtained during very slow expirations at constant flow rates. Fig. 2 contains points read from all curves. TLC was determined separately in the usual manner, but on each occasion we also interrupted the pressure-volume recording to obtain a separate measurement of $\mathrm{TGV}$ at about $50 \%$ VC. The two independent measurements of

TABLE III

Control Lung Function and Response to Hemp Dust

\begin{tabular}{|c|c|c|c|}
\hline Group & A & B & $\mathrm{C}$ \\
\hline $\mathrm{n}$ & 11 & 8 & 6 \\
\hline Age, $y r$ & 40.2 & 49.6 & $31.3^{*}$ \\
\hline Time in industry, $y r$ & 17.1 & 30.4 & $13.3^{*}$ \\
\hline Time in dust, hr:min & $2: 44$ & $1: 51$ & $2: 40$ \\
\hline \multicolumn{4}{|l|}{$\begin{array}{l}\text { Control data (in } \% \text { of predicted } \\
\text { values; average } \pm \mathrm{SE} \text { ) }\end{array}$} \\
\hline $\mathrm{FEV}_{1.0}$ & $102 \pm 4.4$ & $64 \pm 3.7$ & $111 \pm 6.6 \ddagger$ \\
\hline VC & $107 \pm 3.9$ & $86 \pm 5.8 \S$ & $110 \pm 6.9^{*}$ \\
\hline RV & $119 \pm 14.0$ & $203 \pm 18.9 \S$ & $116 \pm 17.9^{*}$ \\
\hline TLC & $111 \pm 4.4$ & $118 \pm 5.7$ & $111 \pm 9.7$ \\
\hline \multicolumn{4}{|l|}{$\begin{array}{l}\text { Average changes during dust } \\
\text { exposure: }\end{array}$} \\
\hline$\Delta \mathrm{FEV}_{1.0}$, liters & -0.34 & -0.27 & $+0.01 * \S$ \\
\hline$\Delta \mathrm{FEV}_{1.0}, \%$ of control & -9.8 & -12.8 & +0.3 \\
\hline$\Delta \mathrm{VC}$, liters & -0.15 & $\overline{-0.45} \|$ & $+0.06(5) \ddagger$ \\
\hline$\Delta \mathrm{VC}, \%$ of control & -2.8 & -12.1 & +1.1 \\
\hline$\Delta \mathrm{RV}$, liters & +0.16 & +0.36 & $+0.17(5)$ \\
\hline$\Delta \mathrm{RV}, \%$ of control & +11.7 & +12.0 & +8.9 \\
\hline$\Delta \mathrm{PEFR}$, liters $/$ sec & -0.44 & -0.80 & +0.10 \\
\hline$\triangle$ PEFR, $\%$ of control & -5.0 & -16.9 & +2.0 \\
\hline$\Delta \dot{\mathrm{V}}_{\max }$ at $50 \% \mathrm{VC}$, liters $/ \mathrm{sec}$ & -0.91 & -0.35 & $+0.10 \|$ \\
\hline$\Delta \dot{\mathrm{V}}_{\max }$ at $50 \% \mathrm{VC}, \%$ of control & -24.2 & $\overline{-21.4}$ & $+3.9 \|$ \\
\hline$\Delta \mathrm{Gaw} / \mathrm{TGV}, 1 / \mathrm{cm} \times \mathrm{sec}$ & -0.005 & -0.011 & $-0.031 * \|$ \\
\hline$\Delta \mathrm{Gaw} / \mathrm{TGV}, \%$ of control & -3.9 & -8.5 & $-20.1 \|$ \\
\hline
\end{tabular}

Group A, Men with chest tightness in dust; control $\mathrm{FEV}_{1.0}>80 \%$ of predicted. Group $\mathrm{B}$, men with chest tightness in dust; control $\mathrm{FEV}_{1.0}<80 \%$ of predicted. Group C, identical with Group C in Table IV. Changes during dust are assessed in absolute values as well as in per cent of control, since Group B has lower control values than $\mathrm{A}$ and $\mathrm{C} . \mathrm{n}=$ No. of subjects (exceptions in parentheses). The significance of the changes during dust exposure is indicated by underlining $(P<0.05)$ and by italics $(P<0.01)$ (paired $t$ test). Group A includes three men, and group B two men in whom duplicate experiments were done (included in Table II B). Here we used the experiment with the most pronounced response for each of these men.

* $P<0.05$, for significant differences between group averages of $\mathrm{B}$ and $\mathrm{C}$ (unpaired $t$ test).

$\ddagger P<0.01$, for significant differences between group averages of $\mathrm{B}$ and $\mathrm{C}$ (unpaired $t$ test).

$\S P<0.01$, for significant differences between group averages of $\mathrm{B}$ with $\mathrm{A}$ and of $\mathrm{C}$ with A (unpaired $t$ test).

$\| P<0.05$, for significant differences between group averages of $\mathrm{B}$ with $\mathrm{A}$ and of $\mathrm{C}$ with A (unpaired $t$ test). (Average control $\mathrm{FEV}_{1.0}$ in $\mathrm{A}$ and $\mathrm{B}$ differ because of selection criterium.) 
TABLE IV

Smoking Habits and Effects of Hemp Dust Exposure

\begin{tabular}{|c|c|c|c|c|c|c|c|}
\hline Group & $\mathbf{n}$ & Age & $\begin{array}{c}\text { Time } \\
\text { in } \\
\text { dust }\end{array}$ & $\begin{array}{c}\underset{\text { Time }}{\text { Time }} \\
\text { hemp }\end{array}$ & $\Delta \mathrm{FEV}_{1.0}$ & $\begin{array}{l}\Delta \dot{\mathrm{V}}_{\max } \text { at } \\
50 \% \text { VC }\end{array}$ & $\begin{array}{l}\text { Chest } \\
\text { tightness }\end{array}$ \\
\hline & & $y r$ & hr:min & $y r$ & liters & liters/sec & \\
\hline Nonsmokers & 13 & 41.3 & $2: 29$ & 23.4 & -0.201 & -0.35 & $9 / 13$ \\
\hline Smokers & 13 & 43.1 & $2: 06$ & 22.9 & $\begin{array}{c}-0.272 \\
\mathrm{NS}\end{array}$ & $\begin{array}{r}-0.87 \\
P<0.05\end{array}$ & $\begin{array}{c}11 / 13 \\
\chi^{2}: N S\end{array}$ \\
\hline
\end{tabular}

Paired comparison of results in 13 nonsmokers matched for age and duration of employment in hemp with 13 cigarette smokers. $\Delta \mathrm{FEV}_{1.0}$ and $\Delta \dot{\mathrm{V}}_{\max }$ at $50 \% \mathrm{VC}$ are average decreases during exposure period. Chest tightness refers to symptoms at end of exposure.

TLC corresponded closely. Fig. 2 shows that, while static recoil pressures remained unaltered after dust, MEFV curves obtained at the same times showed marked decreases of flow rates after dust exposure. In the hemp worker, static recoil pressures were, if anything, slightly increased after dust exposure, when compared with control data at equal thoracic gas volumes (Fig. $3 \mathrm{~A}$ ). This subject was given isoproterenol by inhalation after the post-dust measurements were completed, and another set of static recoil curves was obtained. These were superimposable with those obtained after dust. Fig. $3 \mathrm{~B}$ shows this subject's maximum expiratory flow rates under each of the three conditions (control, after dust, and after isoproterenol), plotted against static lung recoil pressure. After dust, flow rates at equal static recoil pressures are decreased, and after the dilator drug they increase towards the control values.

Prevention and treatment of responses to dust with bronchodilator drugs. Oral administration of $10 \mathrm{mg}$ orciprenaline (Alupent) before dust exposure on Monday prevented the decrease of $\mathrm{FEV}_{1.0}$ and $\mathrm{VC}$ which occurred in four workers during dust exposure on another Monday after administration of a placebo tablet (Table VI). The difference in duration of exposure appears insufficient to explain the marked difference between the effects of exposures on the 2 days.
After completion of the measurements after dust exposure, most subjects were given two or four inhalations of a bronchodilator aerosol (Medihaler-Duo). This usually resulted in marked subjective improvement within $30 \mathrm{~min}$ in those who had symptoms. After isoproterenol, most measurements return to values close to control data, in men with a flow rate response as well as in those with a conductance response. Without treatment, the flow rate response usually persists for several hours $(1,12)$.

Changes of lung function on control days. Five men were studied before and after a period of $3 \mathrm{hr}$ without dust exposure, at the same time of day that dust exposures were usually performed. The average changes of $\mathrm{FEV}_{1.0}, \mathrm{VC}$, and $\mathrm{V}_{\max }$ at $50 \%$ TLC were minimal during the control day $(+0.03$ liter, +0.04 liter; and 0 liters/sec, respectively). For the same men, the average changes during dust exposure on another day were: $\mathrm{FEV}_{1.0},-0.28$ liter; $\mathrm{VC},-0.14$ liter; $\mathrm{V}_{\max }$ at $50 \%$ $\mathrm{VC},-0.9$ liters/sec.

\section{DISCUSSION}

We found two qualitatively different pulmonary function responses to acute hemp dust exposure in hemp workers with a prior history of many years exposure, as well as in healthy subjects exposed for the first time to this dust. One, the flow rate response, consists of a decrease

TABLE V

Dust Exposure at Rest and during Exercise

\begin{tabular}{|c|c|c|c|c|c|c|c|c|c|c|}
\hline \multirow[b]{2}{*}{ Subject } & \multicolumn{5}{|c|}{ At rest } & \multicolumn{5}{|c|}{ Bicycle exercise } \\
\hline & $\begin{array}{l}\text { Time } \\
\text { in } \\
\text { dust }\end{array}$ & $\triangle \mathrm{FEV}_{1.0}$ & $\Delta \mathrm{VC}$ & $\begin{array}{c}\Delta \dot{V}_{\max } \\
\mathbf{5 0 \%} \mathrm{VC}\end{array}$ & $\Delta$ Gaw:TGV & $\begin{array}{l}\text { Time } \\
\text { in } \\
\text { dust }\end{array}$ & $\Delta \mathrm{FEV}_{1,0}$ & $\Delta \mathrm{VC}$ & $\begin{array}{c}\Delta \dot{\mathrm{V}}_{\mathrm{max}} \\
50 \% \mathrm{VC}\end{array}$ & $\Delta$ Gaw: TGV \\
\hline & $h r$ & lilers & liters & liters/sec & $1 / \mathrm{cm} \times \mathrm{sec}$ & $h r$ & liters & liters & liters/sec & $1 / \mathrm{cm} \times \mathrm{sec}$ \\
\hline A & 2 & +0.01 & +0.02 & +0.4 & -0.043 & 2 & -0.13 & -0.36 & -2.1 & +0.026 \\
\hline B & 2 & -0.06 & 0 & -0.6 & -0.035 & 2 & +0.10 & +0.10 & -0.1 & +0.009 \\
\hline $\mathrm{C}$ & 4 & +0.01 & +0.02 & +1.1 & -0.031 & 3 & -0.01 & +0.08 & 0 & +0.034 \\
\hline
\end{tabular}

Values are changes of measurements after dust exposure, compared with control data ( + : increase). 
of maximum flow rates on MEFV curves and of $\mathrm{FEV}_{\mathbf{1 . 0}}$, with a decrease of $\mathrm{VC}$ and an increase of $\mathrm{RV}$, while airway conductance (panting) decreases less or not at all. The other, the conductance response, consists of a decrease of airway conductance in the absence of flow rate, $\mathrm{FEV}_{1.0}$, or lung volume changes.

The subjective symptoms during dust exposure were related to the type of response. Most (15/19) men with chest tightness during exposure had a flow rate response; the remaining four had little or no change in any one measurement. In contrast, all six men without symptoms during exposure had a conductance response.

Although our experience with repeated exposure in single individuals is limited, the available data suggest that the type of response is characteristic for the individual and does not vary grossly with time. Duplicate exposures in five men (in group B, Table II) showed a flow rate response on both occasions. Nearly all men with a flow rate response said that they regularly experienced chest tightness when working on Mondays, and in several of them we had measured decreases of FEV ${ }_{1.0}$ during work on Monday in a previous study (1). One man had a conductance response on two occasions in the present study. On two previous occasions, his FEV $V_{1.0}$ was slightly increased immediately after exposure on Monday. He had never had any symptoms in dust. Symptoms during dust exposure had always been absent or minimal in all hemp workers with a conductance response. However, controlled experiments on the consistency of the response are difficult, since the dustiness of work areas may vary from day-to-day, depending

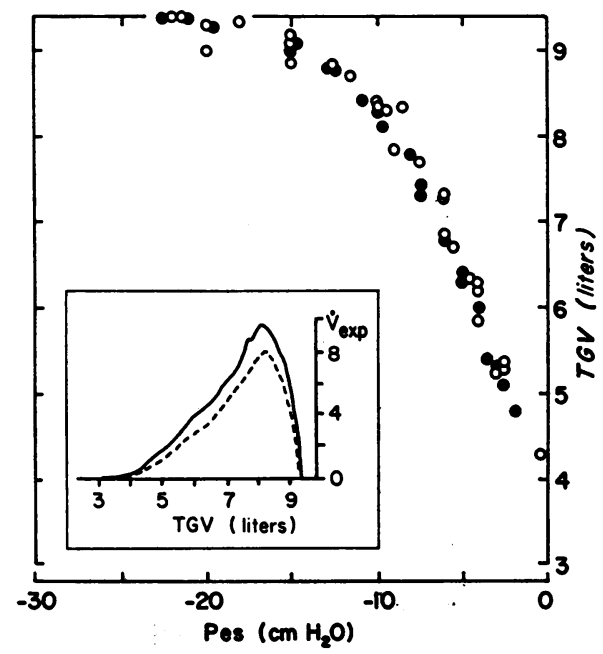

FIGURE 2 Static recoil pressure of the lungs $v s$. thoracic gas volume before $(\bullet)$ and after (O) dust in a healthy subject. Insert: MEFV curves at the same occasions (before, - - - after dust). Pes = esophageal pressure. $V$ in liters/sec.
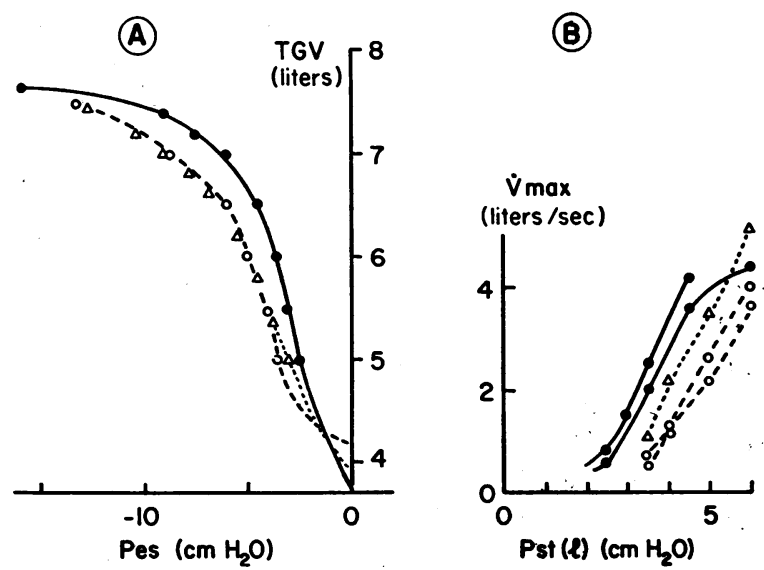

Figure 3 (A) Static recoil curves of the lungs in a hemp worker before $(\bullet)$ and after $(O)$ dust and again after isoproterenol $(\triangle)$. Curves extrapolated to the separately measured value of RV. (B) Maximum flow-static recoil curves in the same subject. Symbols as in part A.

on the quality of the hemp, the amount of natural ventilation, and the number of men at work in a given room.

The type of response was not demonstrably related to age and duration of employment in the industry, nor to possible variations in dust exposure conditions. Thus, it seems likely that the flow rate and conductance responses reflect a difference in response between individuals. Before accepting this conclusion, however, we must discuss whether the differences can be explained by errors or artifacts in our procedures.

In healthy subjects, our conductance values are similar to those of many other investigators who used DuBois' technique (summarized in reference 13) (Gaw: TGV = $0.230 \pm 0.070$ (sD) in 31 men aged 20-29 yr). Curvilinearity of Gaw-TGV graphs and positive volume intercepts on such graphs have only a minor influence on Gaw : TGV ratios (13). This also appears from the work of Guyatt, Alpers, Hill, and Bramley (14), who

TABLE VI

Drug Protection Against Response to Dust

\begin{tabular}{|c|c|c|c|c|c|c|}
\hline \multirow[b]{2}{*}{ Subject } & \multicolumn{3}{|c|}{ Placebo } & \multicolumn{3}{|c|}{ Bronchodilator } \\
\hline & $\begin{array}{c}\text { Time } \\
\text { in } \\
\text { dust }\end{array}$ & $\Delta \mathrm{FEV}_{1.0}$ & $\Delta \mathbf{V C}$ & $\begin{array}{l}\text { Time } \\
\text { in } \\
\text { dust }\end{array}$ & $\Delta \mathrm{FEV}_{1.0}$ & $\Delta \mathrm{VC}$ \\
\hline & $h r: \min$ & liters & liters & hr:min & liters & liters \\
\hline D & $3: 45$ & -0.15 & -0.34 & $2: 45$ & +0.24 & +0.37 \\
\hline $\mathbf{E}$ & $2: 45$ & -0.49 & -0.25 & $2: 30$ & -0.18 & -0.05 \\
\hline $\bar{F}$ & $3: 30$ & -0.63 & -0.44 & $3: 00$ & -0.11 & -0.01 \\
\hline G & $2: 45$ & -0.20 & -0.12 & $2: 30$ & +0.04 & +0.13 \\
\hline Average & $3: 11$ & -0.37 & -0.29 & $2: 41$ & $\mathbf{0}$ & +0.11 \\
\hline
\end{tabular}

Bronchodilator drug, $10 \mathrm{mg}$ orciprenaline orally, before start of dust exposure period. 
furthermore showed that Gaw: TGV ratios do not vary systematically over the work day nor over the work week in a large number of men not exposed to dust. Although panting frequency was not rigorously controlled, the effects of relatively large variations, e.g. from 1 to $3 \mathrm{cps}$, should be minimal even if Raw is markedly frequency dependent (15). The reliability of the $V_{\max }$ changes is strengthened by the fact that two different methods for recording of MEFV curves gave similar results. Maximum flow rates on MEFV curves are subject to effects of volume and flow history during fast expirations (16). We minimized this factor by using only forced expirations starting at TLC, i.e., the same maneuver which is used for the measurement of $F V_{\text {1.o. }}$ The dust-induced changes of $F E V_{1.0}$ are small compared with those seen in severe obstructive lung disease, but they are consistent (see legend to Fig. 1) and several times larger than variations of $F E V_{1.0}$ in the absence of dust exposure in the same subjects. The changes of $\dot{V}_{\max }$ at $50 \% \mathrm{VC}$ and at $60 \%$ TLC are larger than those of $\mathrm{FEV}_{1.0}$, when both are expressed as a percentage of control values. Similarly, in previous studies $V_{\max }$ at $50 \% \mathrm{VC}$ and at $60 \%$ TLC were more sensitive indicators of the effects of bronchoconstrictor aerosols than $F E V_{1.0}, P E F R$, and the ratio $F E V_{1.0}: \mathrm{VC}$ (7). Thus, although changes of $\mathrm{FEV}_{1.0}$ appear to reflect flow rate responses consistently, the measurement of flow rates on the effort-independent part of $\mathrm{MEFV}$ curves is more sensitive in this respect.

Inspirations to TLC may decrease or abolish decreases of Gaw (17) as well as of $V_{\max }(7)$, induced by bronchoconstrictor agents. So far, this effect has been demonstrated only for agents which cause brief effects (lasting minutes), while the effects of hemp dust, without treatment, may last hours. The changes of both Gaw and $\dot{V}_{\max }$ might have been larger if we had avoided the deep inspirations which preceded both measurements in our study. If anything, this would probably have accentuated the difference between the men who showed the two different responses. Also, the changes might have been larger if we had measured Gaw and $V_{\max }$ during or at the end of dust exposure rather than up to 30 min later. Again, this might have increased the difference between the two responses quantitatively.

One might suppose that the conductance response was initially accompanied by flow rate decreases, but that the latter had disappeared, possibly due to repeated deep inspirations, by the time that the MEFV curves were recorded. However during other exposures, several of these men never showed decreases of $F E V_{1.0}$, and usually slight increases, even when this was measured during or immediately after exposure. Thus, these men had no demonstrable flow rate response even before they made more than one maximum inspiration. It is unlikely that the
TABLE VII

Effect of Bronchodilator Drug on Acute Responses to Dust Exposure

\begin{tabular}{|c|c|c|c|c|c|c|}
\hline & \multicolumn{3}{|c|}{$\begin{array}{l}\text { Flow rate response, } \\
\qquad \mathrm{n}=12\end{array}$} & \multicolumn{3}{|c|}{$\begin{array}{l}\text { Conductance response, } \\
\qquad n=5\end{array}$} \\
\hline & a & b & c & a & b & c \\
\hline $\mathrm{FEV}_{1.0}$, liters & 2.99 & 2.60 & $2.94 *$ & 4.56 & 4.56 & 4.72 \\
\hline $\begin{array}{l}\dot{\mathrm{V}}_{\max } \text { at } 50 \% \mathrm{VC}, \\
\quad \text { liters } / \mathrm{sec}\end{array}$ & 2.63 & $1.78 \ddagger$ & $2.52 *$ & 4.84 & 4.84 & 5.668 \\
\hline $\begin{array}{l}\text { PEFR, } \\
\text { liters } / \text { sec }\end{array}$ & 6.39 & $5.60 \ddagger$ & $6.61 *$ & 8.34 & 8.42 & 8.78 \\
\hline $\begin{array}{l}\text { Gaw: TGV } \\
1 / \mathrm{cm} \times \mathrm{sec}\end{array}$ & 0.130 & 0.113 & 0.160 & 0.176 & $0.143 \S$ & 0.176 \\
\hline
\end{tabular}

a,b,c, average values before (a) and after dust exposure (b), and after bronchodilator (c). Subjects with flow rate response are those whose FEV .e decreased at least $\mathbf{0 . 2 0}$ liters while in dust.

$* P<0.01$ for significance of difference with value after dust. $\ddagger P<0.01$ for significance of difference with control value. $\$ P<0.02$ for significance of difference with control value. Differences without symbols are not significant.

conductance response was caused by glottis narrowing or changes in supraglottal airways. The glottis is usually wide open during panting. Partial glottal closure sometimes occurs while the subject learns the panting maneuver but is easily recognized by the extremely low conductance which results. Also, this assumption does not explain why the conductance response occurred only in subjects without symptoms, nor does it explain its disappearance after administration of a bronchial smooth muscle relaxant (Table VII).

With regard to the flow rate response, one might assume that the symptoms of chest tightness which accompany this response lead to an altered breathing pattern, including perhaps frequent deep inspirations, which might abolish any conductance response before it could be measured. However, there is another, more simple, explanation why the flow rate response is usually not accompanied by major decreases of airway conductance (vide infra). Rigorous exclusion of these and yet other possible assumptions to account for the two types of response in terms of procedural artifacts is difficult, but we consider them unlikely explanations for our results. We believe that both responses are caused by contraction of bronchial smooth muscle, since both are abolished by isoproterenol, and that the difference between them can be explained most logically by a difference in the site of the dust effect in the airways.

We suggest that the conductance response reflects dust-induced smooth muscle contraction in relatively large airways, with decreased caliber as a result, while the flow rate response reflects a similar constriction of relatively small airways. This hypothesis agrees with current concepts and data on the factors which deter- 
mine Gaw and $V_{\max }$, as well as with results of other function tests during textile dust exposure.

Anatomical (18) as well as physiological (19) data suggest that relatively large intrathoracic airways are the main site of airway resistance in man. For instance, at a flow rate of 2 liters/sec and a lung volume of $50 \%$ $\mathrm{VC}$, the pressure drop between a segmental bronchus and a point just below the glottis is larger than the pressure drop between the alveoli and a segmental bronchus (see Fig. 7 of Macklem and Wilson [19]). We suggest that hemp dust may constrict smooth muscle in the walls of the larger airways, and that this leads to the conductance response. Since the mechanical properties of these larger airways are only a minor factor in determining maximum flow rates during forced expirations, the conductance decrease is not accompanied by decreases of $V_{\max }$. In fact, smooth muscle contraction may stiffen the walls of these airways and protect them, to some extent, against dynamic compression during forced expirations (20). Thus, one expects $V_{\max }$ to increase rather than to decrease, and this was indeed observed in some men with a conductance response (Fig. $1 \mathrm{C})$.

In our experiments, the conductance response did not lead to subjective respiratory distress. It is of interest that Simonsson, Jacobs, and Nadel (21), who observed large conductance decreases in experiments with bronchoconstrictor aerosols, mention only coughing and tickling in the throat as symptoms in their subjects. The conductance response may be similar to the responses to inert dust observed by DuBois and Dautrebande (22) and to responses to various bronchoconstrictor aerosols and dusts in asthmatic patients. For the latter, Simonsson et al. (21) concluded that they were elicited reflexly by stimulation of cough receptors. This explanation does not fit our results, since our subjects with a conductance response did not cough.

The flow rate response is probably determ ned by a constrictor effect of dust on small airways. In this context, small airways are defined in functional rather than anatomical terms; they are the airways in Mead's "upstream segment," which remain uncompressed during forced expirations. Maximum expiratory flow rates are determined by the resistance of these airways and by the driving pressure across them; the latter equals the lung static recoil pressure (Pst(1)) (23). Since Pst(1) did not decrease after dust in two subjects with a flow rate response, we conclude that increased resistance of the small airways is probably the major cause of the decreased flow rates. This increased resistance could be caused either by a decrease of airway caliber or by an increased length of the "upstream segment." The latter could occur if the large intrathoracic airways would become more collapsible. While such an effect may ac- count for the decreased flow rates sometimes seen after bronchodilation in healthy persons (24), it is unlikely that a bronchoconstrictor agent causes large airway smooth muscle to relax. Therefore, we conclude that the flow rate response is caused by bronchoconstriction in the small airways of the "upstream segment." These airways constitute only a small fraction of total airway resistance (19), and this may explain why conductance only decreases when the flow rate response is very pronounced. Previous studies have shown that decreases of $\mathrm{FEV}_{1.0}$ after exposure to cotton dust or its extracts are accompanied by prolongation of nitrogen washout (4) and by decreases of dynamic lung compliance (25). Since these changes can be explained by regionally different degrees of small airway obstruction, they support our concept of the flow rate response.

Textile dusts, including hemp dust from the rooms where our subjects were exposed, release histamine in human lung tissue in vitro (26) and probably in vivo (1). Extracts of these dusts release histamine and cause chest tightness and functional changes consistent with a flow rate response when aerosolized and inhaled by healthy subjects (25). Since histamine is presumably released from mast cells in lung tissue, it is more likely to affect small airways then larger ones. The flow rate response correlates with the symptoms of chest tightness during dust exposure; the conductance response does not. Since acute symptoms of chest tightness during dust exposure are significantly correlated with the eveniual development of irreversible chronic lung disease in older hemp workers (2), it follows that, to assess the eventual risk of chronic disease, the flow rate response is more relevant than the conductance response. This is supported by the fact that all men with abnormal control lung function had a flow rate response to dust (Table III B). Their responses were more severe (per hour dust exposure) than those of the flow rate responders with normal control data (Table III A). Also, the flow rate response appeared somewhat more pronounced among those who usually smoked cigarettes (Table IV). This is not related to acute effects of smoking, since none of the men smoked during dust exposure. The more severe flow rate response in men with a low $\mathrm{FEV}_{1.0}$ and in those who smoked may be related to the existence of some degree of small airway obstruction before exposure. Similar degrees of smooth muscle contraction would cause more pronounced decreases of the caliber of such airways than of normal ones (27).

The subjects of Table III B have symptoms and function changes characteristic of obstructive lung disease. If increased sensitivity of cough receptors (21) were a general feature of such disease, we would expect a pronounced conductance response in these men. In fact, we found the opposite: conductance responses occurred 
in men without symptoms and with normal control data. Also, the cough reflex induced short lasting responses in the experiments of Simonsson et al. (21), whereas the responses in our study were observed $20-30 \mathrm{~min}$ after the end of exposure.

The pathogenesis of the chronic lung disease in byssinotic hemp and cotton workers (28) is not known. The fact that its development is associated with the flow rate response suggests that both may be caused by the same agent(s), i.e. those which release histamine in human lung, although additional roles of other noxious substances in the dust cannot be excluded. The present data, together with epidemiological evidence (2), suggest that bouts of small airway obstruction, recurring every week, lead to chronic lung damage after many years of exposure to a noxious environmental agent. The mechanisms which lead to this lung damage remain to be elucidated.

Since airborne textile dusts contain particles of many different sizes, one may assume that particle deposition occurs throughout the bronchial tree (29). We will now discuss how the site of bronchial smooth muscle contraction could vary individually, even though small as well as large airways may be exposed to similar amounts of inhaled dust particles.

Experiments with unanesthetized guinea pigs in our laboratory (30) suggest that the response to inhaled histam ne in these animals depends largely on the balance between vagal and sympathetic tone. Individual variations in sensitivity to histamine appeared to be determined principally by variations of sympathetic tone. Sympathetic nerve fibers have been demonstrated in the airway walls of cats (31) and rabbits (32). Our hypothesis assumes that (a) sympathetic tone affects the response of human airways to hemp dust in a manner similar to its effect on the histamine response in guinea pigs, and $(b)$ the distribution of sympathetic nerve fibers in the walls of small and large human airways varies individually. We suggest that men with a flow rate response may have relatively few sympathetic fibers in small airways; the norepinephrine output of these fibers might be insufficient to protect these airways from constriction by locally released histamine. Their large airways might be protected against the conductance response by virtue of the presence of sympathetic nerve fibers in sufficient numbers. In men with a conductance response, the sympathetic fiber distribution might be predominantly to small airways, and a similar argument applies. Macklem (33) found that stimulation of the intact vagosympathetic trunk in dogs caused primarily an increase of peripheral airway resistance in some animals and of large airway resistance in others. Since it is likely that vagal as well as sympathetic efferent fibers were being stimulated, his findings could be explained along the lines of our hypothesis. That sufficient amounts of bronchoconstrictor aerosols or dusts cause a response in most subjects is not in conflict with our hypothesis. The effect of the protection by sympathetic outflow would be to shift the dose-response curve to a higher dose level rather than to abolish all response. Suitable techniques are now available to determine the distribution of sympathetic nerve fibers in airways (31), and our hypothesis can therefore be tested. The present observations may suggest that sympathetic fibers are predominantly distributed to relatively large airways in about $75 \%$ of human males.

Since flow rate responses occurred in men who processed hemp or performed bicycle exercise during exposure, the increased sympathetic outflow during exercise may be insufficient to overcome the effects of locally released histamine, although it may prevent the conductance response (Table $\mathrm{V}$ ). A relatively long acting sympathomimetic drug, orciprenaline (34), prevented or decreased the flow rate response; its effect on the conductance response was not studied. Isoproterenol inhalation after dust exposure reversed both the flow rate and the conductance response; reversal of the flow rate response was incomplete in several subjects.

In a previous study (1), we described hemp workers who had symptoms and an $F E_{1.0}$ decrease while in dust as "reactors;" we called men without such a response "nonreactors." This view must now be modified. The men previously described as "reactors" are those with a flow rate response, while the previous "nonreactors" do in fact respond, albeit with a conductance response rather than with a flow rate response and w:th symptoms.

Several previous investigators have used bronchoconstrictor aerosols or chemically inert dusts to elicit bronchoconstriction in human subjects. Since the effects of these bronchoconstrictors are usually short-lived, few data are available where more than one kind of measurement was performed after each exposure. Thus, most studies on airway conductance do not yield adequate information on flow rates, and vice versa. In our study, the measurement of maximum expiratory flow rates and of $F E V_{1.0}$ proved to be essential for the detection of the effects of an industrial dust which is known to cause lung disease. This conclusion disagrees with currently accepted views on the relative value of flow rate and airway conductance measurements in the assessment of acute bronchoconstrictor responses. DuBois (35) summarized previous studies which showed that Raw may increase twofold during induced bronchoconstriction, without changes of PEFR or FEV 1.0, and that slight dyspnea occurs when Raw has increased threefold. These statements are consistent with our findings in the men with a conductance response, and 
they may well be generally valid for bronchoconstrictor responses in large airways. However, there is so far no evidence that such responses lead to chronic lung disease, while, at least in byssinosis, the flow rate response is associated with chronic lung damage.

There is considerable confusion in the literature with regard to the relative merits of airway conductance and maximum flow rate measurements. For instance, Payne, Chester, and Hsi (36) found that intravenous theophyllin improved flow rates in patients with obstructive lung disease, but the drug did not alter Gaw: TGV ratios. Since these authors felt that any effect of the drug on airways would lead to a change of conductance, they suggested a central effect of theophyllin to account for the improved flow rates. However, their finding can be readily explained if this drug, given parenterally, affects mainly small airways and thus increase $V_{\max }$, while large airway conductance (and thus total Gaw) changes little.

We do not wish to suggest that measurements of airway conductance are of minor significance in the study of lung disease. Rather, we believe that the present results contribute to a better perspective on all methods used to determine airway caliber and its alterations. The control data in our subjects (healthy and diseased) show significant correlations between all measurements of flow rates and conductance, with correlation coefficients ranging from $+0.440(P<0.05)$ for Gaw : TGV vs. $\mathrm{FEV}_{1.0}$ to $0.816(P<0.01)$ for $\mathrm{FEV}_{1.0} v s$. $\mathrm{V}_{\max }$ at $50 \%$ VC. This demonstrates merely that, in patients with obstructive lung disease, $\mathrm{FEV}_{1.0}, \mathrm{~V}_{\max }$, and airway conductance all tend to deviate from the normal. To detect gross deviations from normal in a group of subjects, any one of these measurements may give a valid answer. Since all of them reflect aspects of airway obstruction, the significant correlations are not surprising. However, when studying more subtle changes in pulmonary function, such as those induced by hemp dust and other bronchoactive agents, the different physiological significance of changes in maximum expiratory flow rates and changes in airway conductance should be taken into account.

\section{ACKNOWLEDGMENTS}

We are indebted to A. Anton, Dr. A. Barbero, J. Bernabeu, J. Canales, A. Canales Belmonte, J. A. Delcerro, M. Lopez Serna, R. Martinez, Dr. R. S. F. Schilling, and all subjects for their assistance and cooperation in the field study. The facilities for our field laboratory were kindly put at our disposal by the management of Hilaturas Caralt y Perez S. A. We thank Riker Laboratories, Inc. (Northridge, Calif.) for a gift of Medihaler-Duo, and C. H. Boehringer Sohn, Ingelheim am Rhein, Germany, for a gift of Alupent and placebo tablets.

This work was supported in part by a grant from the National Center for Urban and Industrial Health. U. S. Public Health Service (UI-00435).

\section{REFERENCES}

1. Bouhuys, A., A. Barbero, S.-E. Lindell, S. A. Roach, and R. S. F. Schilling. 1967. Byssinosis in hemp workers. Arch. Environ. Health. 14: 533.

2. Bouhuys, A., A. Barbero, R. S. F. Schilling, and K. P. van de Woestijne. 1969. Chronic respiratory disease in hemp workers. Amer. J. Med. 46: 526.

3. McKerrow, C. B., M. McDermott, J. C. Gilson, and R. S. F. Schilling. 1958. Respiratory function during the day in cotton workers: a study in byssinosis. Brit. J. Ind. Med. 15: 75 .

4. Arnoldsson, H., A. Bouhuys, and S.-E. Lindell. 1963. Byssinosis. Differential diagnosis from bronchial asthma and chronic bronchitis. Acta Med. Scand. 173: 761.

5. Bouhuys, A. 1963. Byssinosis in a cotton weaving mill. Arch. Environ. Health. 6: 465.

6. Belin, L., A. Bouhuys, W. Hoekstra, M. B. Johansson, S.-E. Lindell, and J. Pool. 1965. Byssinosis in cardroom workers in Swedish cotton mills. Brit. J. Ind. Med. 22: 101.

7. Bouhuys, A., V. R. Hunt, B. M. Kim, and A. Zapletal. 1969. Maximum expiratory flow rates in induced bronchoconstriction in man. J. Clin. Invest. 48: 1159.

8. Bouhuys, A. 1969. Recent applications of volume displacement body plethysmographs. In Symposium on Body Plethysmography. K. P. van de Woestijne and A. B. DuBois, editors. S. Karger AG., Basel. In press.

9. Peters, J. M., J. Mead, and W. F. Van Ganse. 1969. A simple flow-volume device for measuring ventilatory functions in the field: results on workers exposed to low levels of TDI (toluene diisocyanate). Amer. Rev. Resp. Dis. 99: 617.

10. Bouhuys, A. 1966. Airflow control by auditory feedback: respiratory mechanics and wind instruments. Science (Washington). 154: 797.

11. Boren, H. G., R. C. Kory, and J. C. Syner. 1966. The Veterans Administration-Army cooperative study of pulmonary function. II. The lung volume and its subdivisions in normal men. Amer. J. Med. 41: 96.

12. McDermott, M., P. J. Nicholls, J. Edwards, and J. Skidmore. 1968. The physiological, immunological and pharmacological effects of inhaled cotton dusts. 2nd International Conference on Respiratory Diseases in Textile Workers, Alicante.

13. Pelzer, A., and M. L. Thomson. 1966. Effect of age, sex, stature, and smoking habits on human airway conductance. J. Appl. Physiol. 21: 469.

14. Guyatt, A. R., J. H. Alpers, I. D. Hill, and A. C. Bramley. 1967. Variability of plethysmographic measurements of airways resistance in man. J. Appl. Physiol. 22: 383.

15. Grimby, G., T. Takishima, W. Graham, P. Macklem, and J. Mead. 1968. Frequency dependence of flow resistance in patients with obstructive lung disease. J. Clin. Invest. $47: 1455$.

16. Bouhuys, A., and B. Jonson. 1967. Alveolar pressure, air flow rate and lung inflation in man. J. Appl. Physiol. 22: 1086.

17. Nadel, J. A., and D. F. Tierney. 1961. Effect of a previous deep inspiration on airway resistance in man. J. Appl. Physiol. 16: 717.

18. Weibel, E. R. 1963. Morphometry of the human lung. Springer-Verlag AG., Berlin.

19. Macklem, P. T., and N. J. Wilson. 1965. Measurement of intrabronchial pressure in man. J. Appl. Physiol. 20: 653. 
20. Olsen, C. R., A. E. Stevens, and M. B. McIlroy. 1967. Rigidity of tracheae and bronchi during muscular constriction. J. Appl. Physiol. 23: 27.

21. Simonsson, B. G., F. M. Jacobs, and J. A. Nadel. 1967. Role of autonomic nervous system and the cough reflex in the increased responsiveness of airways in patients with obstructive airway disease. J. Clin. Invest. 46: 1812 .

22. DuBois, A. B., and L. Dautrebande. 1958. Acute effects of breathing inert dust particles and of carbachol aerosol on the mechanical characteristics of the lungs in man. Changes in response after inhaling sympathomimetic aerosols. J. Clin. Invest. 37: 1746.

23. Mead, J., J. M. Turner, P. T. Macklem, and J. B. Little. 1967. Significance of the relationship between lung recoil and maximum expiratory flow. J. Appl. Physiol. 22: 95.

24. van de Woestijne, K. P., B. M. Kim, A. Zapletal, J. van Wayenburg, and A. Bouhuys. 1968. Forced expiratory flow rates and airway resistance in bronchoconstriction and dilation. Fed. Proc. 27: 280.

25. Bouhuys, A., and P. J. Nicholls. 1967. The effect of cotton dust on respiratory mechanics in man and in guinea pigs. In Inhaled Particles and Vapours. Pergamon Press Ltd., Oxford. II: 75.

26. Nicholls, P. J., G. R. Nicholls, and A. Bouhuys. 1967. Histamine release by compound $48 / 80$ and textile dusts from lung tissue in vitro. In Inhaled Particles and Vapours. Pergamon Press Ltd., Oxford. II : 69.

27. Bouhuys, A. 1967. Response to inhaled histamine in bronchial asthma and in byssinosis. Amer. Rev. Resp. Dis. 95: 89.

28. Bouhuys, A., L. J. Heaphy, Jr., R. S. F. Schilling, and J. W. Welborn. 1967. Byssinosis in the United States. N. Engl.J. Med. 277: 170.
29. Morrow, P. E. 1969. Dynamics of dust removal from the lower airways: Measurements and interpretations based upon radioactive aerosols. In Airway Dynamics, Physiology and Pharmacology. A. Bouhuys, editor. Charles C Thomas Publisher, Springfield. In press.

30. Dennis, M. W., and J. S. Douglas. 1969. Control of bronchomotor tone in spontaneously breathing unanesthetized guinea pigs. In Airway Dynamics, Physiology and Pharmacology. A. Bouhuys, editor. Charles C Thomas Publisher, Springfield. In press.

31. Dahlström, A., K. Fuxe, T. Hökfelt, and K. Norberg. 1966. Adrenergic innervation of the bronchial muscle of the cat. Acta Physiol. Scand. 66: 507.

32. Blümcke, S. 1968. Experimental and morphological studies on the efferent bronchial innervation. I. The peribronchial plexus. Beitr. Pathol. Anat. Allg. Pathol. 137: 239.

33. Macklem, P. T. 1969. Partitioning of the pressure drop in the airways. In Airway Dynamics, Physiology and Pharmacology. A. Bouhuys, editor. Charles C Thomas Publisher, Springfield. In press.

34. Morton, J. W., and L. G. Ostensoe. 1963. A comparative study of aerosol, oral, and intravenous administration of bronchodilators in asthma, with the use of isoproterenol (isuprel). TH 152, and aminophylline. J. $\mathrm{Al}$ lergy. $34: 16$.

35. DuBois, A. B. 1963. Impairment of pulmonary mechanics. Arch. Environ. Health. 6: 133.

36. Payne, C. B., Jr., E. H. Chester, and B. P. Hsi. 1967. Airway responsiveness in chronic obstructive pulmonary disease. Amer. J. Med. 42: 554. 